\title{
Abstracta Iranica
}

Revue bibliographique pour le domaine irano-aryen

«Imported painted pottery from Asia Minor to Daskyleion in the Achaemenid period ", in : W. Henkelman \& A. Kuhrt, eds., A Persian Perspective, Essays in memory of Heleen Sancisi-Weerdenburg. Leiden, 2003, pp. 203-226. (Achaemenid History XIII).

\section{Rémy Boucharlat}

\section{(2) OpenEdition Journals}

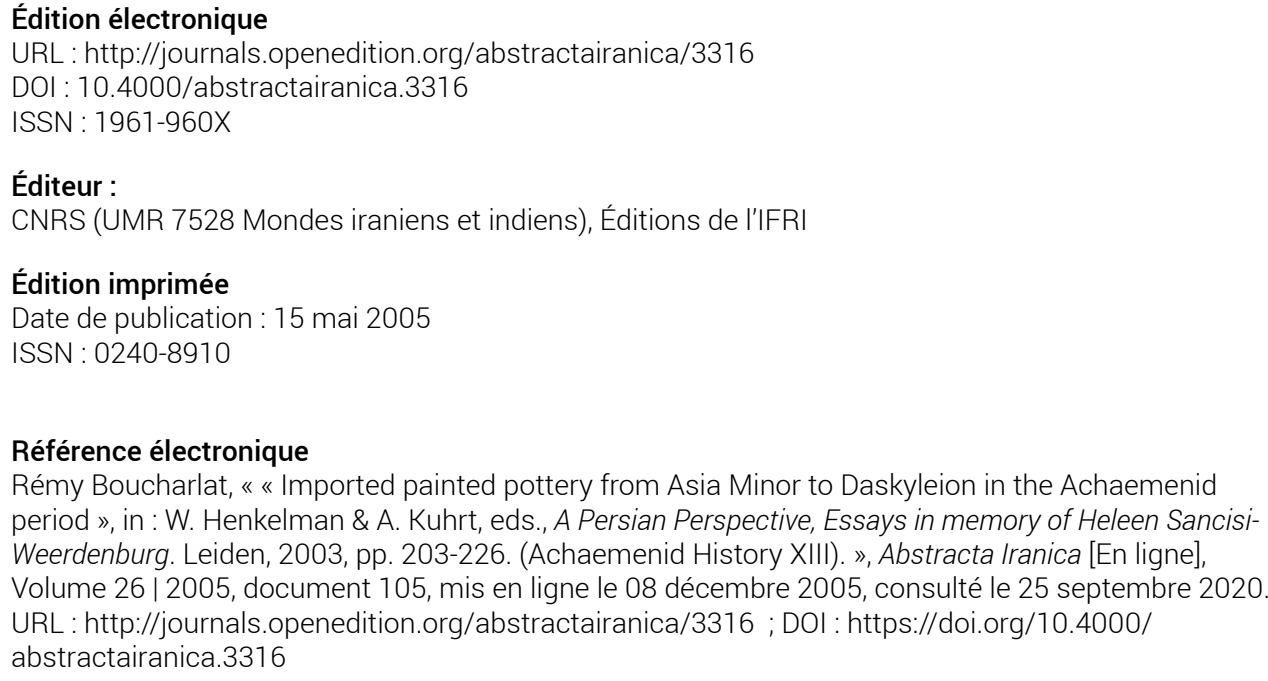

Ce document a été généré automatiquement le 25 septembre 2020.

Tous droits réservés 
« Imported painted pottery from Asia Minor to Daskyleion in the Achaemenid period », in : W. Henkelman \& A. Kuhrt, eds., A Persian Perspective, Essays in memory of Heleen Sancisi-Weerdenburg. Leiden, 2003, pp. 203-226. (Achaemenid History XIII).

Rémy Boucharlat

Devenue capitale de la satrapie de Phrygie hellespontique, Daskyleion continue d'importer des céramiques peintes de Grèce, d'Ionie et de Phrygie, mais de ces deux dernières régions en bien plus faible quantité qu'aux époques antérieures et jusqu'à la seconde moitié du $6^{\mathrm{e}} \mathrm{s}$. Pour l'A. cette diminution correspond simplement au déclin de la production de la céramique peinte en Asie Mineure (Milet et Phrygie) et non pas à une baisse des échanges.

INDEX

Thèmes : 3.2.2. Pré-Achéménides et Achéménides 
AUTEURS

RÉMY BOUCHARLAT

CNRS - Lyon 